\title{
Associated factors of poor treatment outcomes in patients with giant cell arteritis: clinical implication of large vessel lesions
}

Takahiko Sugihara ( $\nabla$ takahikosugihara03240925@gmail.com )

Tokyo Medical and Dental University https://orcid.org/0000-0002-7181-7494

Hitoshi Hasegawa

Ehime University

Haruhito A Uchida

Okayama University

Hajime Yoshifuji

Kyoto University

Yoshiko Watanabe

Kawasaki Medical School

\section{Eisuke Amiya}

The University of Tokyo

Yasuhiro Maejima

Tokyo Medical and Dental University

Masanori Konishi

Tokyo Medical and Dental University

Yohko Murakawa

Shimane University

Noriyoshi Ogawa

Hamamatsu University

Shunsuke Furuta

Chiba University

Yasuhiro Katsumata

Tokyo Women`s Medical University

Yoshinori Komagata

Kyorin University

Taio Naniwa

Nagoya City University

Takahiro Okazaki

St. Marianna University

Yoshiya Tanaka 
University of Occupational and Environmental Health

\section{Tsutomu Takeuchi}

Keio University

\section{Yoshikazu Nakaoka}

National Cerebral and Cardiovascular Center Research Institute

\section{Yoshihiro Arimura}

Kyorin University

\section{Masayoshi Harigai}

Tokyo Women`s Medical University

\section{Mitsuaki Isobe}

Tokyo Medical and Dental University

\section{Research article}

Keywords: giant cell arteritis, large-vessel lesions, poor treatment outcomes, remission, relapse, glucocorticoids therapy

Posted Date: March 26th, 2020

DOI: https://doi.org/10.21203/rs.2.22145/v2

License: (c) (1) This work is licensed under a Creative Commons Attribution 4.0 International License. Read Full License

Version of Record: A version of this preprint was published at Arthritis Research \& Therapy on April 7th, 2020. See the published version at https://doi.org/10.1186/s13075-020-02171-6. 


\section{Abstract}

Background Relapses frequently occur in giant cell arteritis (GCA) patients treated with conventional immunosuppressive therapy, and identification of associated factors with poor treatment outcomes is relevant to adjust treatment appropriately. Methods We enrolled 139 newly-diagnosed GCA patients treated with glucocorticoids between 2007 and 2014 in a retrospective, multi-center registry. Patients were diagnosed with temporal artery biopsy, 1990 American College of Rheumatology classification criteria, or large-vessel lesions (LVLs) detected by imaging based on the modified classification criteria. Poor treatment outcomes (non-achievement of clinical remission by week 24 or relapse during 52 weeks) were evaluated. Clinical remission was defined as absence of clinical signs and symptoms in cranial and large-vessel areas, polymyalgia rheumatica (PMR), and elevation of C-reactive protein (CRP) levels. A patient was determined to have relapse if he/she had either one of the signs and symptoms that newly appeared or worsened after achieving clinical remission. Re-elevation of CRP without clinical manifestations was considered as relapse if other causes such as infection were excluded and the treatment was intensified. Associated factors with poor treatment outcomes were analyzed by using the Cox proportional hazard model. Results Cranial lesions, PMR, and LVLs were detected in $77.7 \%, 41.7 \%$, and $52.5 \%$ of the enrolled patients, respectively. Treatment outcomes were evaluated in 119 newlydiagnosed patients who were observed for more than 24 weeks. The mean initial dose of prednisolone was $0.76 \mathrm{mg} / \mathrm{kg} /$ day, and $29.4 \%$ received any concomitant immunosuppressive drugs at baseline. Overall, 41 (34.5\%) of the 119 patients had poor treatment outcomes; 13 did not achieve clinical remission by week 24 , and 28 had relapse after achieving clinical remission. Cumulative rates of the events of poor treatment outcomes in patients with and without LVLs were $47.5 \%$ and $17.7 \%$, respectively. A multivariable model showed the presence of LVLs at baseline was significantly associated with poor treatment outcomes (adjusted hazard ratio [HR] 3.54, 95\% Cl 1.52-8.24, $\mathrm{p}=0.003$ ). Cranial lesions and PMR did not increase the risk of poor treatment outcomes. Conclusion Initial treatment intensity in treatment algorithm of GCA could be determined based upon the presence or absence of LVLs detected by imaging at baseline.

\section{Background}

Giant cell arteritis (GCA) is a vasculitis syndrome that usually develops in patients aged 50 years and over. GCA is characterized by cranial symptoms due to lesions in the superficial temporal artery, the maxillary artery, and the ophthalmic artery, and large-vessel lesions (LVLs) in the aorta or its branches. An epidemiological study from a Japanese nationwide survey in 1998 showed lower prevalence of GCA in Japan than in western countries and almost same clinical features of GCA (1).

The subclavian artery is a key location for LVLs in GCA, and Brack et al. proposed definition of largevessel GCA (LV-GCA) as subclavian artery vasculitis in aged populations(2). Aortic aneurysm is also an important clinical feature of GCA that is related to mortality $(3,4)$. Aortic aneurysm is more complicated in GCA patients than in the general population (5). Modified American College of Rheumatology (ACR) GCA classification criteria proposed by the Vasculitis Clinical Research Consortium (6) included LVLs as 
typical clinical findings of GCA (7), and more recently, in line with evolution of imaging diagnosis of LVLs $(8,9)$, wall thickening by enhanced CT or MRI or ${ }^{18}$ fluorodeoxyglucose (FDG) uptake in the LVLs by FDGpositron emission tomography (PET) are recognized to be a common clinical findings of GCA $(8,10)$.

High dose of glucocorticoids (GCs) monotherapy is a standard induction regimen of GCA, with the rapid resolution of signs and symptoms of temporal arteritis and polymyalgia rheumatica (PMR) (11), but previous observational studies reported that the disease worsened in $30-50 \%$ of the patients during tapering of GCs $(6,12,13)$, and long-term GCs therapy is required to prevent relapses of the disease. Increasing cumulative GCs dose is associated with drug-related adverse events (AEs) (14) and treatment strategy that is able to reduce cumulative dose of GCs is valuable $(11,15)$. Recent studies tried to resolve the unmet medical needs of the treatment of GCA (16-18), and efficacy of tocilizumab is clearly demonstrated in terms of achievement of sustained clinical remission without GC. In the new era of the treatment, identification of associated factors for treatment response to conventional immunosuppressive therapy without biologics may help to guide the precision medicine of GCA (11).

Thus, we assessed treatment outcomes of conventional immunosuppressive therapy without biologics, based on the pre-defined criteria of clinical remission and relapse. This is the first study in Japan by using data of the multi-center retrospective cohort of GCA including patients diagnosed with imaging findings of LVLs, which identified clinical findings at baseline associated with poor treatment outcomes during 52 weeks.

\section{Methods}

\section{Database.}

Twenty-three university hospitals and referring hospitals with sufficient experience treating vasculitides participated in this retrospective multi-center study. All investigators were members of Japan Research Committee of the Ministry of Health, Labour, and Welfare for Intractable Vasculitis (JPVAS). All incident cases of clinically diagnosed GCA from 2007 to 2014 who had started GC therapy were enrolled in the JPVAS large-vessel vasculitis (LVV) cohort. The patients were diagnosed in each facility based on temporal arterial biopsy (TAB), 1990 ACR GCA classification criteria, imaging findings of LVL based on the modified ACR GCA classification criteria (6) Definition of clinical remission and relapse was determined by the study group before start of the data collection in 2014. Investigators at each participating facility examined medical records retrospectively, and assessed clinical remission and relapse based on the pre-defined criteria. Data for two years after starting GCs were collected, using predefined case-report form at four, eight, 24, 52, 76 and 104 weeks after start of treatment. One-year outcomes were examined in the present study. Investigators at each participating facility reported the date of achievement of clinical remission, disease status at these time points, date of relapse, and clinical manifestations at the relapse including imaging findings and treatment intensification. Definition of clinical remission and relapse are described below. 


\section{Outcomes.}

Primary endpoint was an event of poor treatment outcomes (non-achievement of clinical remission by week 24 or relapse after achieving clinical remission during 52 weeks). Clinical remission was defined as absence of active disease. The active disease at baseline was defined as having clinical signs and symptoms in cranial and large-vessel areas (Additional file: Table S1) or PMR, and/or elevation of Creactive protein (CRP) levels. We discriminated persisted ischemic signs and symptoms (i.e., visual manifestations or claudication) from the damage of GCA at week 24 after start of treatment as follows; if the signs and symptoms of active disease at baseline persisted without worsening for six months or longer and CRP level was normalized, these were not considered as clinical findings of active disease at week 24. A patient was determined to have relapse if he/she had either one of the signs and symptoms that newly appeared or worsened after achievement of clinical remission, or deterioration of imaging findings of LVL. Re-elevation of CRP level above the laboratory normal limit (CRP $<0.3 \mathrm{mg} / \mathrm{dl}$ ) without clinical manifestations was considered as relapse only if other causes such as infection were excluded and the treatment was intensified.

\section{Confirmation of relapse by the study group.}

Three investigators ( $\mathrm{HAU}, \mathrm{HY}, \mathrm{YN}$ ) independently reviewed clinical findings at the relapse, treatment intensification and clinical course after the relapse in a manner to blind imaging data at baseline about $L V L$, and confirmed whether the data met the definition of relapse in the present study, especially, in the relapse cases who did not have clinical signs and symptoms of active disease and showed an elevated CRP level. Finally, one patient was judged as infection but not relapse, because the patient was diagnosed with miliary tuberculosis after intensification of the treatment.

\section{Safety.}

Safety was assessed by collecting information for 0-52 weeks after start of treatment. This information included development of serious infections, fractures, cardiovascular lesions requiring hospitalization or prolonged hospitalization, cerebrovascular lesions requiring hospitalization or prolonged hospitalization, gastrointestinal bleeding or perforation requiring hospitalization or prolonged hospitalization, diabetes mellitus requiring drug therapy, glaucoma or a cataract requiring drug therapy or eye surgery, psychiatric symptoms requiring drug therapy, and death.

\section{Collection of imaging data of LVL.}


The site investigators reported wall thickening, wall edema, stenosis, aneurysm, or dissection in anatomical sites of lesions of aortic branches (carotid, vertebral, brachiocephalic, subclavian, axillary, pulmonary, renal, and iliac/femoral arteries) and aortic lesions (ascending aorta, aortic arch, thoracic descending aorta, and abdominal aorta) based on the results of at least one of computed tomography (CT), CT angiography (CTA), magnetic resonance imaging (MRI), or magnetic resonance angiography (MRA). Data were also collected on FDG uptake in the arterial wall using FDG-PET. Information about lesions of cerebral, basilar, coronary, and mesenteric arteries were also collected.

\section{Statistics.}

Student's $t$ test and the Mann-Whitney test were used to compare continuous variables depending on their distribution, and the chi-squared test and Fisher's exact test were used for categorical variables. The patients who dropped out within 24 weeks after treatment were excluded from the analysis of clinical remission and relapse. In the analysis of poor treatment outcomes, patients who did not achieve clinical remission by week 24 were deemed to have had an event of poor treatments outcome at week 0 as described in the previous study (18). Patients with relapse after achievement of clinical remission were considered to have had an event at the date of relapse. Univariable and multivariable analysis for associated factors with the event of poor treatment outcomes during 52 weeks were conducted by using the Cox proportional hazard model. Omnibus test was used as Goodness-of-fit test. Cumulative rates and median time of the first event of poor treatment outcomes during 52 weeks were analyzed using the Kaplan-Meier method and the log-rank test. A sensitivity analysis was implemented by using relapse after achievement of clinical remission as an event. All analyses were performed using SPSS version 21 (IBM, Armonk, NY, USA). All reported $p$-values are two-tailed and the level of significance is $P<0.05$.

\section{Results}

\section{Patient characteristics.}

Case report forms of 139 newly diagnosed patients were assessed (Table 1$)$. All patients $(n=139)$ were Asian. The mean (SD) age was 73.8 (7.7) years, mean weight (SD) was $50.9(10.4) \mathrm{kg}$, and $66.9 \%$ were women. Age of onset was 70 and older in 98 patients, 60-69 in 38, and 50-59 in 3. Median disease duration was 3.1 months (interquartile range [IQR] 1.6-6.3). Overall, 108 (77.7\%) of the 139 had clinical signs and symptoms of cranial lesions, 36 (25.9\%) clinical signs and symptoms of LVLs, and 58 (41.7\%) PMR. TAB was conducted in 86 patients and $70(50.4 \%)$ of the 139 patients were biopsy-proven GCA. Imaging examinations of LVLs were performed in 135 (97.1\%) patients, and 97 received enhanced CT or CT angiography, 50 enhanced MRI or MR angiography, 31 carotid ultrasonography, 61 cardiac sonography, 14 non-enhanced CT, 17 non-enhanced MRI, and 38 PET-CT. LVLs were detected in 73 (52.5\%) of the 139 patients. Thirty-five of the 73 patients with LVLs were also confirmed with data on PET-CT. Imaging data were summarized in Table 2. Lesions of subclavian artery, any aortic branches, or aorta were found in $42(57.5 \%), 54(74.0 \%)$, or 50 (68.5\%) of the 73 patients, respectively, and stenosis of 
subclavian artery or aortic aneurysm was observed in $14(19.2 \%)$ or $7(9.6 \%)$, respectively. Any vascular damage of large vessels by imaging data was observed in 31 (42.5\%) of the 73 patients. Sixteen (38.1\%) of the 42 patients with lesions of subclavian arteries detected by imaging data had clinical signs and symptoms of upper limbs (claudication, decreased or absent radial pulse, or blood pressure asymmetry $>10 \mathrm{~mm} \mathrm{Hg}$ ). One had pulmonary hypertension due to stenosis of pulmonary artery. Annuloaortic ectasia and aortic insufficiency caused by vasculitis were not reported.

\section{Diagnosis of GCA.}

Overall, 30 (21.6\%) of the 139 patients were diagnosed by both positive TAB and positive imaging, 40 $(28.8 \%)$ by positive TAB, and $43(30.9 \%)$ by positive imaging based on the modified ACR GCA classification criteria (6). Twenty-six (18.7\%) did not have positive TAB or positive imaging, and were diagnosed based on the 1990 ACR GCA classification criteria.

\section{Clinical remission by week 24 .}

Of the 139 newly-diagnosed patients with GCA, clinical remission was evaluated in 119 (85.6\%) patients who were observed for 24 weeks or longer, and 20 patients were excluded from the analysis (Figure 1). Patient characteristics of the 119 patients were same as those of the 139 patients of entire cohort (Additional file: Table S2).

The initial mean dose (SD) of PSL was $0.76(0.23) \mathrm{mg} / \mathrm{kg} /$ day, and $35(29.4 \%)$ of the 119 patients received any concomitant immunosuppressive drugs for induction therapy. Methotrexate (MTX) was administered for initial treatment in 20 patients, azathioprine (AZA) in 11, and cyclophosphamide (CY) in 4. No patients received biologic agents. Headache and/or abnormal temporal artery were observed in 87 patients at baseline and improved at week 4 in 84 (96.6\%), and disappeared in all patients after week 8 . Jaw claudication was found in 45 patients at baseline and disappeared in 44 (97.8\%) by week 24 . Twenty patients had persisted signs and symptoms without worsening at week 24 (visual manifestations 12 , neck 1, and upper limb 7), and CRP levels were normalized in the all 20 patients. Thus, the 20 patients were deemed not to have active disease at week 24. Total 106 patients achieved clinical remission by week 24 (Figure 1).

Clinical courses of the thirteen patients without clinical remission (i.e., worsening of clinical signs and symptoms or persisted elevation of CRP throughout 24 weeks) were as follows: one dissection and rupture of ascending aorta and post-cardiac arrest encephalopathy 11 days after treatment; one worsening of claudication of lower limbs at week 24; one progression of stenosis of vertebral artery at week 24; one acute heart failure and post-cardiac arrest encephalopathy at week 52; one deterioration of claudication of lower legs at week 24; one deterioration of jaw claudication at week 24; six subclinical 
arteritis of LVLs with persisted elevation of CRP; one subclinical arteritis of cranial lesions with persisted elevation of CRP.

\section{Relapse after achievement of clinical remission.}

Relapse after achievement of clinical remission was reported in total of 28 patients; 9 between week 0 and 24, 19 between week 24 and 52 (Figure 1). Mean time to relapse of patients was 307 days $(95 \% \mathrm{Cl}$ 283-332). The median dose of PSL at the time of relapse was $8.0 \mathrm{mg} /$ day (IQR 5-10). Cranial signs and symptoms were reported in 5 (17.9\%) of the 28 relapse patients; headache in four, jaw claudication in one, and visual disturbance in zero. PMR was reported in five $(17.9 \%)$ and constitutional symptoms in four (14.3\%). Clinical signs and symptoms of LVLs were not observed at the relapse. Elevation of CRP without clinical signs and symptoms followed by treatment intensification was reported in $14(50.0 \%)$ of the 28 relapse patients. Four of the 14 patients showed deterioration of imaging findings of LVLs with following clinical course: one progression of stenosis of left subclavian and ascending aorta, one dissection of descending thoracic aorta, one expansion of abdominal aorta, and one expansion of right subclavian artery. Eight of the 14 patients had relapse of subclinical LVLs with re-elevation of CRP, and two had subclinical cranial lesions with re-elevation of CRP. Overall, PSL dose was increased in 11 patients, and immunosuppressant were added in 18 patients of the 28 patients with relapse. MTX was started in 12 patients, AZA in 2, tacrolimus in 3 , and $\mathrm{CY}$ in 1 . Two patients with clinical signs and symptoms of active disease at the relapse did not have information about treatment intensification.

\section{Clinical characteristics of patients with the event of poor treatment outcomes}

Overall, 41(34.5\%) of the 119 patients had the event of poor treatment outcomes (i.e., non-achievement of clinical remission by week 24 or relapse after achieving remission during 52 weeks) (Figure 1). Two of the 78 patients without the event of poor treatment outcomes dropped out because of serious adverse events (AEs). Patients with the event of poor treatment outcomes had less cranial signs and symptoms and more LVLs, especially aortic lesions, at baseline detected by imaging examinations (Table 3). Frequency of PMR and comorbidities, median CRP at baseline, mean weight, mean PSL doses at week $0,4,8$, and 12 were similar between the two groups.

\section{Associated factors of the event of poor treatment outcomes in patients with GCA.}

In multivariable analysis, age, sex, any cranial lesions, and PMR were selected as covariates of interest, and presence of the LVL was only the significantly associated factor of the event of poor treatment outcomes during 52 weeks (adjusted HR 3.53, 95\% Cl 1.52-8.24, p=0.003) (Table 4). 


\section{Associated factors of relapse in patients who achieved clinical remission.}

Relapse was evaluated in 106 patients who achieved clinical remission by week 24. In univariable analysis, associated factors with relapse were similar to those with the event of poor treatment outcomes (Additional file: Table S3). Presence of any aortic lesions, but not any lesions of aortic branches was a significant factor of relapse. Mean time to relapse of patients with LVLs was significantly shorter than that of patients without LVLs $(p=0.01)$ (Figure 2B). Cumulative rate of relapse after achievement of clinical remission in patients with and without LVLs was $37.4 \%$ and $14.4 \%$, respectively. Multivariable analysis showed that presence of the LVL was only the significantly associated factor of relapse after achievement of clinical remission during 52 weeks (adjusted HR 4.41, 95\% Cl 1.62-12.0, p=0.004) (Additional file: Table S3).

\section{Safety.}

AEs during 52 weeks in the 119 patients are shown in table S4 of additional file. Serious infections occurred in 9 (13.2\%) of 68 LVL patients and in 10 (19.6\%) of 51 non-LVL patients. Five patients died during the observational period. AE leading to death in the patients with LVLs were Pneumocystis jirovecii pneumonia and cerebral infarction, ischemic heart disease after dissection of descending thoracic aorta, and sudden death of unknown origin after expansion of abdominal aorta in one patient for each, and those in the patients without LVLs were miliary tuberculosis and sudden death in one patient for each. Cerebrovascular event was reported $(n=1)$ but was unclear due to vasculitis.

\section{Discussions}

Almost $35 \%$ of the patients with GCA had the event of poor treatment outcomes during 52 weeks in the multi-centric retrospective cohort study in Japan; $11 \%$ was not able to achieve clinical remission by week 24 , and $24 \%$ had relapse after achievement of clinical remission. We have demonstrated that presence of LVLs detected by imaging studies at baseline was significantly associated with the event of poor treatment outcomes. A sensitivity analysis using relapse alone as an event also showed association with LVLs. Interestingly, among LVLs, any aortic lesions are more likely to be associated with the event of poor treatment outcomes. These data suggest that GCA patients with LVLs, especially aortic lesions, may be resistant to initial conventional immunosuppressive therapy without biologics.

The present study showed that mean age at diagnosis, male to female ratio, frequency of cranial signs and symptoms and PMR were almost same as epidemiological findings in western countries $(7,13,19$ 21). Prevalence and distribution of LVLs were various among previous cohorts $(4,19,20,22-25)$ by different inclusion criteria and imaging modalities used for the diagnosis. In our cohort, LVLs were detected in about half of GCA patients, and one-fifth of the patients were diagnosed as having GCA using 
LV imaging without satisfying the 1990 GCA ACR classification criteria. These are almost same as a recent RCT, which adopted the eligibility criteria including imaging for recruitment of active patients (18, $19,26)$. The distribution of LVLs in our study was almost similar to recent studies of GCA with LVLs (23, 27).

Serious outcomes, such as dissection and rupture of aneurysms, were reported in previous studies (2830). Progressive vascular damage of LVLs during 52 weeks was reported in six (8.8\%) of the 68 patients with LVLs in the present study, and these values were almost same as previous reports $(20,22)$.

The evaluation of disease activity and vascular damage of LVV is challenging (31-33). Ocular manifestations and large-artery complications were common damage in patients with GCA (34). In our study, upper limb claudication and visual disturbance that persisted without worsening for six months or longer were deemed as inactive disease at week 24 . However, the imaging progression of LVLs might be underestimated in the present study, because follow-up imaging studies were not conducted in all of patients.

Treatment responses of GCA with LVLs are controversial among observational studies (20, 21, 35-38). The present study showed only presence of LVLs at baseline was an associated factor of nonachievement of clinical remission or relapse, while initial PSL dose, PSL tapering speed during the initial 12 weeks, and immunosuppressive drug use at baseline were not. However, associated factors of relapse or severe complications were various (i.e. age, hypertension, diabetes at GCA diagnosis, ischemic heart disease, cranial signs and symptoms, CRP at baseline, and dose of PSL at baseline) (13, 30, 38-41). Differential treatment response and discrepancy of the results in each cohort may be influenced by the definition of clinical remission and relapse, prevalence of LVLs, and severity of LVLs at baseline.

CRP elevation without clinical signs and symptoms was not reliable indicator of relapse of cranial lesions and PMR(42), while clinical signs and symptoms of active GCA were not necessarily observed in patients with progression of LVLs $(22,36,43-46)$. Active LVLs of GCA without clinical signs and symptoms were demonstrated by PET-CT $(47,48)$. Previous studies also showed CRP elevation without clinical signs and symptoms was a common finding during tapering of PSL dose (42) or at relapse of the disease in GCA cohorts $(13,17)$. The present study also showed that elevation or re-elevation of CRP without clinical signs and symptoms was a common finding in the active GCA with LVLs at baseline or relapse. The reason of treatment intensification reported in $43 \%$ of the relapsed cases was the elevated CRP and/or vascular structural progression, which were considered as the residual vascular inflammation of LVLs without clinical signs and symptoms.

There are some limitations associated with the retrospective design of this study. First, selection bias due to retrospective design should be considered, but the risk is small because suspected patients with GCA who were referred to the participating hospitals of this study were identified using data from electronic medical records, and the investigators enrolled all cases. Second, 20 patients were excluded from the outcome analysis due to short follow-up period. But these patients had no relapse, and did not impact interpretation of data. Third, a uniform assessment of LVL at baseline and relapse, especially PET- 
CT, which was not covered by health insurance before 2018 in Japan, was not implemented for all the patients. However, imaging might be rather more frequently examined for diagnosis of GCA in Japan than in other countries, and the frequency of LVL at baseline was as expected based on previous reports (19, 20). Fourth, the drug therapy was selected at the discretion of an attending physician, and the present study was not able to interpret optimal protocol of glucocorticoid therapy and benefit of immunosuppressive drugs for GCA. Fifth, 139 newly-diagnosed patients were enrolled from 23 facilities, and number of patients per facility may be fewer than previous studies in western countries. However, the number of enrolled patients was higher than expected, since a prevalence rate of Japanese GCA patients was much lower than western countries (1).

\section{Conclusions}

LVLs are detected by imaging in about half of the Japanese patients at baseline in the present study. LVLs, especially any aortic lesions, were an associated factor for poor treatment outcomes in the conventional immunosuppressive therapy without biologics. Initial treatment intensity could be determined based upon the presence or absence of LVLs. Our research results will be important for establishing a future treatment strategy of GCA.

\section{List Of Abbreviations}

ACR: American College of Rheumatology, AEs: adverse events, AZA: azathioprine, CRP: C-reactive protein, CY: cyclophosphamide, FDG: ${ }^{18}$ fluorodeoxyglucose, GCA: giant cell arteritis (GCA), GCs: Glucocorticoids, JPVAS: Japan Research Committee of the Ministry of Health, Labour, and Welfare for Intractable Vasculitis, LVLs: Large-vessel lesions, LV: large-vessel, MTX : methotrexate, PET: positron emission tomography, PMR: polymyalgia rheumatica , PSL: prednisolone, TAB: temporal arterial biopsy.

\section{Declarations}

\section{Ethics approval and consent to participate}

This study was conducted in accordance with the Declaration of Helsinki and the Ethical Guidelines for Epidemiological Research in Japan. The institutional review board of Tokyo Medical and Dental University as main center (approval number: M2000-2084-01) and the additional 23 institutions approved our retrospective study without personally identifiable information. Patients received posters informing the present study, or the posters were displayed in outpatient clinic of each facility.

\section{Consent for publication}

Not applicable

\section{Availability of data and materials}


All of the data supporting the conclusions of this article are included within the article.

\section{Competing interests}

TS has received research grants and/or honoraria from Abbvie Japan Co., Ltd., AsahiKASEl Co., Ltd., Astellas Pharma Inc., Ayumi Pharmaceutical, Bristol Myers Squibb K.K., Chugai Pharmaceutical Co., Ltd., Daiichi Sankyo., Eli Lilly Japan K.K., Mitsubishi-Tanabe Pharma Co., Ono Pharmaceutical, Pfizer Japan Inc., Takeda Pharmaceutical Co. Ltd., and UCB Japan Co. Ltd.. Tokyo Medical and Dental University received unrestricted research grants for Department of Lifetime Clinical Immunology from Ayumi Pharmaceutical Corporation, Chugai Pharmaceutical Co., Ltd., CSL Behring K.K., Japan Blood Products Organization, and UCB Japan Co. Ltd. HH has received honoraria from Chugai Pharmaceutical Co., Ltd., Takeda Pharmaceutical Co. Ltd., Mitsubishi-Tanabe Pharma Co., Astellas Pharma Inc., Bristol Myers Squibb K.K., Pfizer Japan Inc., Eli Lilly Japan K.K., AsahiKASEl Co., Ltd., Teijin Pharma Ltd, and Abbvie Japan Co., Ltd.. HAU belongs to the Department of Chronic Kidney Disease and Cardiovascular Disease which is endowed by Chugai pharmaceutical, MSD, Boehringer Ingelheim and Kawanishi Holdings. HY has received lecture fees from Chugai Pharmaceutical Co., Ltd. and Nihon Medi-Physics Co., Ltd. YW have received honoraria from Chugai Pharmaceutical Co., Ltd.. EA belongs to the Department of Therapeutic Strategy for Heart Failure, Graduate School of Medicine, University of Tokyo, which is endowed by Actelion Pharmaceuticals Japan Ltd., Otsuka Pharmaceutical, NIPRO CORPORATION, Terumo Corp., Senko Medical Instrument Mfg., Century Medical Inc., Kinetic Concepts Inc., St. Jude Medical. EA has received honoraria from Takeda Pharmaceutical Co. Ltd., Bayer Yakuhin. Ltd., Otsuka Pharmaceutical Co. Ltd. YM have received honoraria from Chugai Pharmaceutical Co., Ltd.. MK have nothing to declare. YM has received honoraria from Abbvie, Astellas, Ayumi Pharmaceutical, Bristol Myers Squibb, Chugai Pharmaceutical, Eisai Pharmaceutical, Janssen Pharmaceutical, Kissei Pharmaceutical, Nippon Kayaku, Pfizer Pharmaceutical, Takeda Pharmaceutical, UCB Pharmaceutical, and has received research grant support from Asahi Kasei Pharma, Chugai Pharmaceutical, Daiichi Sankyo, Eisai Pharmaceutical, Mitsubishi Tanabe Pharma, Nippon Kayaku, Ono Pharmaceutical, Gilead Sciences Inc, Janssen Pharmaceutical, and Teijin Pharma. NO and SF have nothing to declare. YK has received honoraria from Chugai Pharmaceutical Co., Ltd., Glaxo-Smithkline K.K., Sanofi K.K., Pfizer Japan Inc., and Asahi Kasei Pharma Corp. YK has received consulting fees from Chugai, Kyowa Hakko Kirin, Asahi Kasei, UCB and speakers' fees from Bristol-Myers Squibb, Eli Lilly, Janssen, Novartis, Daiichi Sankyo, AbbVie, Nippon Shinyaku, Towa. TN has received research grants and lecture fees from Chugai Pharmaceutical Co., Ltd.. TO has received research grants from Chugai Pharmaceutical Co., Ltd., Eisai Pharmaceutical., and Actelion. YT has received consulting fees, speaking fees, and/or honoraria from Daiichi-Sankyo, Astellas, Pfizer, Mitsubishi-Tanabe, Bristol-Myers, Chugai, YL Biologics, Eli Lilly, Sanofi, Janssen, UCB and has received research grants from Mitsubishi-Tanabe, Takeda, Bristol-Myers, Chugai, Astellas, Abbvie, MSD, Daiichi-Sankyo, Pfizer, Kyowa- Kirin, Eisai, Ono. TT has received research grants from Astellas, Chugai, Daiichi Sankyo, Takeda, AbbVie, Asahi Kasei, Mitsubishi Tanabe, Pfizer, Eisai, AYUMI, Nippon Kayaku, and Novartis, has received consulting fees from Astra Zeneca, Eli Lilly, Novartis, Mitsubishi Tanabe, AbbVie, Nippon Kayaku, Janssen, Astellas, Taiho, Chugai, Taisho Toyama, GlaxoSmithKline, and UCB, and has served on speakers' fees for AbbVie, Bristol-Myers Squibb, Chugai, Mitsubishi Tanabe, 
Pfizer, Astellas, Daiichi Sankyo, Eisai, Sanofi, Teijin, Takeda, and Novartis. YN has received research grants from Bayer Yakuhin,Ltd, and has received consulting fees and/or lecture fees and/or research grants from Chugai, has received consulting fees and/or lecture fees from AbbVie, and has received lecture fees from Astellas, Pfizer, MSD, Daiichi Sankyo, Kowa. YA has received honoraria from Mitsubishi Tanabe Pharma Co., Nippon Shinyaku Co., Ltd., Chugai Pharmaceutical Co.,Ltd., Teijin Pharma, Ltd., Asahi Kasei Corporation, AbbVie GK, F. Hoffmann-La Roche, Ltd., GlaxoSmithKline K.K., KYORIN Pharmaceutical Co.,Ltd., Kyowa Hakko Kirin Company, Limited, and Astellas Pharma Inc. MH has received research grants and/or honoraria from Abbott Japan Co., Ltd.; Astellas Pharma Inc.; BristolMyers Squibb K.K.; Chugai Pharmaceutical Co., Ltd.; Eisai Co., Ltd.; Janssen Pharmaceutical K.K.; Mitsubishi Tanabe Pharma Co.; Santen Pharmaceutical Co., Ltd.; Takeda Pharmaceutical Co., Ltd.; Teijin Pharma, Ltd.; and Pfizer Japan Inc. MI has received research grants and/or honoraria from Chugai, Ono, Otsuka, Teijin, Mitsubishi-Tanabe and Daiichi Sankyo.

\section{Funding}

This work was supported by grants from the Ministry of Health, Labour and Welfare, Japan (H29nanchitou (nan)-ippan-018) and the Japan Agency for Medical Research and Development (AMED) (JP17ek0109121).

\section{Authors' contributions}

T Sugihara and $\mathrm{M}$ Harigai were responsible for conception and design, data collection and analysis, critical revision, and manuscript writing. $\mathrm{HH}, \mathrm{HAU}, \mathrm{HY}, \mathrm{YN}$ YW, YA, and MI were responsible for conception and design, data collection and analysis, and critical revision. EA, YM, MK, YM, NO, SF, YK, YK, TN, TO, YT, and TT were responsible for data collection and analysis, and critical revision. All authors read and approved the final manuscript.

\section{Acknowledgements}

The authors would like to acknowledge all investigators in Japan Research Committee of the Ministry of Health, Labour, and Welfare for Intractable Vasculitis (JPVAS). In addition to the authors, the following investigators and institutions participated in this study: Department of Internal Medicine, Juntendo University Koshigaya Hospital (Shigeto Kobayashi); Division of Rheumatology, Endocrinology and Nephrology, Hokkaido University Graduate School of Medicine (Tetsuya Horita); Division of Endocrinology and Metabolism, Hematology, Rheumatology and Respiratory Medicine, Department of Internal Medicine, Faculty of Medicine, Kagawa University (Hiroaki Dobashi); Department of Nephrology and Dialysis, Kitano Hospital, Tazuke Kofukai Medical Research Institute (Eri Muso); Department of Hematology, Oncology, Nephrology, and Rheumatology, Akita University School of Medicine (Atsushi Komatsuda); Niigata Rheumatic Center (Satoshi Ito); Niigata Prefectural Shibata Hospital (Noriyuki Homma); Department of Cardiovascular Surgery, Kawasaki Medical School (Kazuo Tanemoto); Department of Cardiovascular Medicine, University of Tokyo Graduate School of Medicine (Hiroshi Akazawa, Issei Komuro); Department of Rheumatology and Clinical Immunology, Saitama Medical Center, Saitama 
Medical University (Koichi Amano); Department of Immunology and Rheumatology, Clinical Neuroscience and Neurology, Endocrinology and Metabolism, Nagasaki University Graduate School of Biomedical Sciences (Atsushi Kawakami); Division of Nephrology, Department of Laboratory Medicine, Institute of Medical, Pharmaceutical and Health Sciences, Faculty of Medicine, Kanazawa University (Takashi Wada); Division of Clinical Immunology, Graduate School of Comprehensive Human Sciences, University of Tsukuba (Taichi Hayashi); Kurobe City Hospital (Shinichi Takeda).

\section{References}

1. Kobayashi S, Yano T, Matsumoto Y, Numano F, Nakajima N, Yasuda K, et al. Clinical and epidemiologic analysis of giant cell (temporal) arteritis from a nationwide survey in 1998 in Japan: the first government-supported nationwide survey. Arthritis Rheum. 2003;49:594-8.

2. Brack A, Martinez-Taboada V, Stanson A, Goronzy JJ, Weyand CM. Disease pattern in cranial and large-vessel giant cell arteritis. Arthritis Rheum. 1999;42:311-7.

3. Nuenninghoff DM, Hunder GG, Christianson TJ, McClelland RL, Matteson EL. Mortality of large-artery complication (aortic aneurysm, aortic dissection, and/or large-artery stenosis) in patients with giant cell arteritis: a population-based study over 50 years. Arthritis Rheum. 2003;48:3532-7.

4. Kermani TA, Warrington KJ, Crowson CS, Ytterberg SR, Hunder GG, Gabriel SE, et al. Large-vessel involvement in giant cell arteritis: a population-based cohort study of the incidence-trends and prognosis. Ann Rheum Dis. 2013;72:1989-94.

5. Robson JC, Kiran A, Maskell J, Hutchings A, Arden N, Dasgupta B, et al. The relative risk of aortic aneurysm in patients with giant cell arteritis compared with the general population of the UK. Ann Rheum Dis. 2015;74:129-35.

6. Kermani TA, Warrington KJ, Cuthbertson D, Carette S, Hoffman GS, Khalidi NA, et al. Disease Relapses among Patients with Giant Cell Arteritis: A Prospective, Longitudinal Cohort Study. J Rheumatol. 2015;42:1213-7.

7. Hunder GG, Bloch DA, Michel BA, Stevens MB, Arend WP, Calabrese LH, et al. The American College of Rheumatology 1990 criteria for the classification of giant cell arteritis. Arthritis Rheum. 1990;33:1122-8.

8. Dejaco C, Ramiro S, Duftner C, Besson FL, Bley TA, Blockmans D, et al. EULAR recommendations for the use of imaging in large vessel vasculitis in clinical practice. Ann Rheum Dis. 2018.

9. Prieto-Gonzalez S, Depetris M, Garcia-Martinez A, Espigol-Frigole G, Tavera-Bahillo I, Corbera-Bellata $M$, et al. Positron emission tomography assessment of large vessel inflammation in patients with newly diagnosed, biopsy-proven giant cell arteritis: a prospective, case-control study. Ann Rheum Dis. 2014;73:1388-92.

10. Mukhtyar C, Guillevin L, Cid MC, Dasgupta B, de Groot K, Gross W, et al. EULAR recommendations for the management of large vessel vasculitis. Ann Rheum Dis. 2009;68:318-23. 
11. Hellmich B, Agueda A, Monti S, Buttgereit F, de Boysson H, Brouwer E, et al. 2018 Update of the EULAR recommendations for the management of large vessel vasculitis. Ann Rheum Dis. 2019.

12. Proven A, Gabriel SE, Orces C, O'Fallon WM, Hunder GG. Glucocorticoid therapy in giant cell arteritis: duration and adverse outcomes. Arthritis Rheum. 2003;49:703-8.

13. Labarca C, Koster MJ, Crowson CS, Makol A, Ytterberg SR, Matteson EL, et al. Predictors of relapse and treatment outcomes in biopsy-proven giant cell arteritis: a retrospective cohort study. Rheumatology (Oxford). 2016;55:347-56.

14. Wilson JC, Sarsour K, Collinson N, Tuckwell K, Musselman D, Klearman M, et al. Serious adverse effects associated with glucocorticoid therapy in patients with giant cell arteritis (GCA): A nested case-control analysis. Semin Arthritis Rheum. 2017;46:819-27.

15. Stone JH. Foreword: clinical challenges of diagnosing and managing giant cell arteritis. Rheumatology (Oxford). 2018;57:ii1-ii2.

16. Hoffman GS, Cid MC, Rendt-Zagar KE, Merkel PA, Weyand CM, Stone JH, et al. Infliximab for maintenance of glucocorticosteroid-induced remission of giant cell arteritis: a randomized trial. Ann Intern Med. 2007;146:621-30.

17. Seror R, Baron G, Hachulla E, Debandt M, Larroche C, Puechal X, et al. Adalimumab for steroid sparing in patients with giant-cell arteritis: results of a multicentre randomised controlled trial. Ann Rheum Dis. 2014;73:2074-81.

18. Stone JH, Tuckwell K, Dimonaco S, Klearman M, Aringer M, Blockmans D, et al. Trial of Tocilizumab in Giant-Cell Arteritis. N Engl J Med. 2017;377:317-28.

19. Tuckwell K, Collinson N, Dimonaco S, Klearman M, Blockmans D, Brouwer E, et al. Newly diagnosed vs. relapsing giant cell arteritis: Baseline data from the GiACTA trial. Semin Arthritis Rheum. 2017;46:657-64.

20. Muratore F, Kermani TA, Crowson CS, Green AB, Salvarani C, Matteson EL, et al. Large-vessel giant cell arteritis: a cohort study. Rheumatology (Oxford). 2015;54:463-70.

21. de Boysson H, Daumas A, Vautier M, Parienti JJ, Liozon E, Lambert M, et al. Large-vessel involvement and aortic dilation in giant-cell arteritis. A multicenter study of 549 patients. Autoimmun Rev. 2018;17:391-8.

22. de Boysson H, Liozon E, Lambert M, Parienti JJ, Artigues N, Geffray L, et al. 18F-fluorodeoxyglucose positron emission tomography and the risk of subsequent aortic complications in giant-cell arteritis: A multicenter cohort of 130 patients. Medicine (Baltimore). 2016;95:e3851.

23. Prieto-Gonzalez S, Arguis P, Garcia-Martinez A, Espigol-Frigole G, Tavera-Bahillo I, Butjosa M, et al. Large vessel involvement in biopsy-proven giant cell arteritis: prospective study in 40 newly diagnosed patients using CT angiography. Ann Rheum Dis. 2012;71:1170-6.

24. Gonzalez-Gay MA, Garcia-Porrua C, Pineiro A, Pego-Reigosa R, Llorca J, Hunder GG. Aortic aneurysm and dissection in patients with biopsy-proven giant cell arteritis from northwestern Spain: a population-based study. Medicine (Baltimore). 2004;83:335-41. 
25. Garcia-Martinez A, Hernandez-Rodriguez J, Arguis P, Paredes P, Segarra M, Lozano E, et al. Development of aortic aneurysm/dilatation during the followup of patients with giant cell arteritis: a cross-sectional screening of fifty-four prospectively followed patients. Arthritis Rheum. 2008;59:42230.

26. Unizony SH, Dasgupta B, Fisheleva E, Rowell L, Schett G, Spiera R, et al. Design of the tocilizumab in giant cell arteritis trial. Int J Rheumatol. 2013;2013:912562.

27. Grayson PC, Maksimowicz-McKinnon K, Clark TM, Tomasson G, Cuthbertson D, Carette S, et al. Distribution of arterial lesions in Takayasu's arteritis and giant cell arteritis. Ann Rheum Dis. 2012;71:1329-34.

28. Evans JM, Bowles CA, Bjornsson J, Mullany CJ, Hunder GG. Thoracic aortic aneurysm and rupture in giant cell arteritis. A descriptive study of 41 cases. Arthritis Rheum. 1994;37:1539-47.

29. Nuenninghoff DM, Hunder GG, Christianson TJ, McClelland RL, Matteson EL. Incidence and predictors of large-artery complication (aortic aneurysm, aortic dissection, and/or large-artery stenosis) in patients with giant cell arteritis: a population-based study over 50 years. Arthritis Rheum. 2003;48:3522-31.

30. Kermani TA, Warrington KJ, Crowson CS, Hunder GG, Ytterberg SR, Gabriel SE, et al. Predictors of Dissection in Aortic Aneurysms From Giant Cell Arteritis. J Clin Rheumatol. 2016;22:184-7.

31. Sreih AG, Alibaz-Oner F, Kermani TA, Aydin SZ, Cronholm PF, Davis T, et al. Development of a Core Set of Outcome Measures for Large-vessel Vasculitis: Report from OMERACT 2016. J Rheumatol. 2017;44:1933-7.

32. Aydin SZ, Direskeneli H, Sreih A, Alibaz-Oner F, Gul A, Kamali S, et al. Update on Outcome Measure Development for Large Vessel Vasculitis: Report from OMERACT 12. J Rheumatol. 2015;42:2465-9.

33. Kermani TA, Cuthbertson D, Carette S, Hoffman GS, Khalidi NA, Koening CL, et al. The Birmingham Vasculitis Activity Score as a Measure of Disease Activity in Patients with Giant Cell Arteritis. J Rheumatol. 2016;43:1078-84.

34. Kermani TA, Sreih AG, Cuthbertson D, Carette S, Hoffman GS, Khalidi NA, et al. Evaluation of damage in giant cell arteritis. Rheumatology (Oxford). 2018;57:322-8.

35. de Boysson H, Liozon E, Lambert M, Dumont A, Boutemy J, Maigne G, et al. Giant-Cell Arteritis: Do We Treat Patients with Large-Vessel Involvement Differently? Am J Med. 2017;130:992-5.

36. Garcia-Martinez A, Arguis P, Prieto-Gonzalez S, Espigol-Frigole G, Alba MA, Butjosa M, et al. Prospective long term follow-up of a cohort of patients with giant cell arteritis screened for aortic structural damage (aneurysm or dilatation). Ann Rheum Dis. 2013.

37. Czihal M, Piller A, Schroettle A, Kuhlencordt P, Bernau C, Schulze-Koops H, et al. Impact of cranial and axillary/subclavian artery involvement by color duplex sonography on response to treatment in giant cell arteritis. J Vasc Surg. 2015;61:1285-91.

38. de Boysson H, Lambert M, Liozon E, Boutemy J, Maigne G, Ollivier Y, et al. Giant-cell arteritis without cranial manifestations: Working diagnosis of a distinct disease pattern. Medicine (Baltimore). 2016;95:e3818. 
39. Hocevar A, Rotar Z, Jese R, Semrl SS, Pizem J, Hawlina M, et al. Do Early Diagnosis and Glucocorticoid Treatment Decrease the Risk of Permanent Visual Loss and Early Relapses in Giant Cell Arteritis: A Prospective Longitudinal Study. Medicine (Baltimore). 2016;95:e3210.

40. Salvarani C, Della Bella C, Cimino L, Macchioni P, Formisano D, Bajocchi G, et al. Risk factors for severe cranial ischaemic events in an Italian population-based cohort of patients with giant cell arteritis. Rheumatology (Oxford). 2009;48:250-3.

41. Salvarani C, Cimino L, Macchioni P, Consonni D, Cantini F, Bajocchi G, et al. Risk factors for visual loss in an Italian population-based cohort of patients with giant cell arteritis. Arthritis Rheum. 2005;53:293-7.

42. Stone JH, Tuckwell K, Dimonaco S, Klearman M, Aringer M, Blockmans D, et al. Glucocorticoid Dosages and Acute-Phase Reactant Levels at Giant Cell Arteritis Flare in a Randomized Trial of Tocilizumab. Arthritis Rheumatol. 2019;71:1329-38.

43. Prieto-Gonzalez S, Garcia-Martinez A, Tavera-Bahillo I, Hernandez-Rodriguez J, Gutierrez-Chacoff J, Alba MA, et al. Effect of glucocorticoid treatment on computed tomography angiography detected large-vessel inflammation in giant-cell arteritis. A prospective, longitudinal study. Medicine (Baltimore). 2015;94:e486.

44. Muratore F, Kermani TA, Crowson CS, Koster MJ, Matteson EL, Salvarani C, et al. Large vessel dilatation in giant cell arteritis: a different subset of disease? Arthritis Care Res (Hoboken). 2017.

45. Kermani TA, Diab S, Sreih AG, Cuthbertson D, Borchin R, Carette S, et al. Arterial lesions in giant cell arteritis: A longitudinal study. Semin Arthritis Rheum. 2018.

46. Espitia O, Neel A, Leux C, Connault J, Espitia-Thibault A, Ponge T, et al. Giant cell arteritis with or without aortitis at diagnosis. A retrospective study of 22 patients with longterm followup. J Rheumatol. 2012;39:2157-62.

47. Grayson PC, Alehashemi S, Bagheri AA, Civelek AC, Cupps TR, Kaplan MJ, et al. (18) FFluorodeoxyglucose-Positron Emission Tomography As an Imaging Biomarker in a Prospective, Longitudinal Cohort of Patients With Large Vessel Vasculitis. Arthritis Rheumatol. 2018;70:439-49.

48. Quinn KA, AhIman MA, Malayeri AA, Marko J, Civelek AC, Rosenblum JS, et al. Comparison of magnetic resonance angiography and (18)F-fluorodeoxyglucose positron emission tomography in large-vessel vasculitis. Ann Rheum Dis. 2018;77:1165-71.

\section{Tables}

Table 1. Demographic and clinical features of the giant cell arteritis cohort at baseline 


\begin{tabular}{|c|c|}
\hline Characteristics & Value \\
\hline Age, years, mean $\pm S D,(n=139)$ & $73.8 \pm 7.7$ \\
\hline Female patients, \% $(n=139)$ & 66.9 \\
\hline Weight, $\mathrm{kg}$, mean $\pm \mathrm{SD},(\mathrm{n}=139)$ & $50.9 \pm 10.4$ \\
\hline GCA ACR classification criteria, \% $(n=139)$ & 78.4 \\
\hline Modified GCA classification criteria, \% $(n=139)$ & 99.3 \\
\hline TAB performed, \% $(n=139)$ & 61.9 \\
\hline TAB positive, \% $(n=139)$ & 50.4 \\
\hline Imaging performed, \% $(\mathrm{n}=139)$ & 96.6 \\
\hline Imaging positive, $\%(\mathrm{n}=139)$ & 52.5 \\
\hline Signs and symptoms of cranial lesions, $\%(n=139)$ & 77.7 \\
\hline Headache, \% $(n=139)$ & 61.2 \\
\hline Abnormal temporal artery, \% $(n=139)$ & 59.0 \\
\hline Jaw claudication, \% $(n=139)$ & 36.0 \\
\hline Visual disturbance, $\%(\mathrm{n}=139)$ & 23.7 \\
\hline Visual loss, \% ( $\mathrm{n}=139)$ & 4.3 \\
\hline Signs and symptoms ${ }^{\mathrm{a}}$ of LVL, \% $(\mathrm{n}=139)$ & 25.9 \\
\hline Neck, \% $(n=136)$ & 10.3 \\
\hline Upper limbs, \% $(n=135)$ & 11.8 \\
\hline Lower limbs, \% $(\mathrm{n}=133)$ & 3.0 \\
\hline Chest or abdominal bruit, $\%(n=131)$ & 9.2 \\
\hline Fever, \% $(n=137)$ & 32.1 \\
\hline Constitutional symptoms, \% $(n=132)$ & 75.8 \\
\hline Polymyalgia rheumatica, \% (n=139) & 41.7 \\
\hline \multicolumn{2}{|c|}{ CRP, mg/dl, median (interquartile range), $(n=139) 7.2(3.3-11.2)$} \\
\hline Albumin, $\mathrm{mg} / \mathrm{dl}$, mean $\pm \mathrm{SD},(\mathrm{n}=124)$ & $3.1 \pm 0.6$ \\
\hline Ischemic heart disease, $\%(n=138)$ & 7.2 \\
\hline Cerebrovascular disease, \% $(n=135)$ & 14.1 \\
\hline Chronic lung disease, $\%(n=137)$ & 8.0 \\
\hline
\end{tabular}




\begin{tabular}{lc} 
Hypertension, \% $(\mathrm{n}=138)$ & 44.9 \\
\hline Diabetes Mellitus, \% $(\mathrm{n}=138)$ & 21.0 \\
\hline Hyperlipidemia, \% $(\mathrm{n}=138)$ & 25.3 \\
\hline Osteoporosis, \% $(\mathrm{n}=121)$ & 21.5 \\
\hline Dementia, \% $(\mathrm{n}=137)$ & 1.5 \\
\hline
\end{tabular}

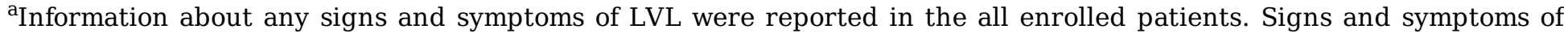
neck included tenderness of carotid arteries, carotid bruit or neck claudication. Signs and symptoms of upper limb included arm claudication, decreased or absent radial pulse, or blood pressure asymmetry >10 mm Hg. Lower limb included leg claudication or decreased or absent pulse of lower limb.

LVL, large-vessel lesions; LV, large-vessel; ACR, American College of Rheumatology; CRP, C-reactive protein.

Table 2. Imaging findings in the patients with LVL $\left(n=73^{a}\right)$ 


\begin{tabular}{|c|c|c|c|c|}
\hline & $\begin{array}{l}\text { Any imaging } \\
\text { findings }^{\mathrm{b}}\end{array}$ & $\begin{array}{l}\text { Wall thickening, wall edema, or FDG } \\
\text { uptake }\end{array}$ & Stenosis & Aneurysm \\
\hline Left carotid, \% & 41.1 & 37.0 & 8.2 & 0 \\
\hline Right carotid, \% & 32.9 & 31.5 & 2.7 & 0 \\
\hline Vertebral, \% & 8.2 & 5.5 & 6.8 & 0 \\
\hline Brachiocephalic, \% & 31.5 & 30.1 & 2.7 & 0 \\
\hline Left subclavian, \% & 53.4 & 46.6 & 11.0 & 1.4 \\
\hline Right subclavian, \% & 43.8 & 39.7 & 8.2 & 0 \\
\hline Left axillary, \% & 20.5 & 16.4 & 5.5 & 0 \\
\hline Right axillary, \% & 16.4 & 15.1 & 0 & 1.4 \\
\hline Pulmonary, \% & 1.4 & 0 & 1.4 & 0 \\
\hline Coronary, \% & 2.6 & 0 & 2.6 & 0 \\
\hline Ascending aorta, \% & 31.5 & 28.8 & 0 & 4.1 \\
\hline Aortic arch, \% & 47.9 & 47.9 & 0 & 2.7 \\
\hline Descending thoracic & 49.3 & 47.9 & 0 & 0 \\
\hline \multicolumn{5}{|l|}{ aorta, \% } \\
\hline Abdominal aorta, \% & 53.4 & 53.4 & 0 & 2.7 \\
\hline Renal, \% & 6.8 & 2.7 & 2.7 & 1.4 \\
\hline Hepatic, \% & 1.4 & 0 & 0 & 1.4 \\
\hline Mesenteric, \% & 1.4 & 0 & 1.4 & 0 \\
\hline Iliac or femoral artery, \% & 19.2 & 16.4 & 6.8 & 1.4 \\
\hline
\end{tabular}

$\mathrm{LVL}=$ large-vessel lesions. FDG $={ }^{18}$ fluorodeoxyglucose

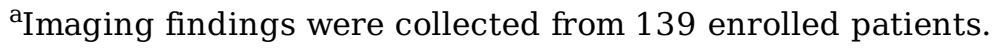

${ }^{\mathrm{b}}$ Any imaging findings include wall thickening, wall edema, arterial FDG uptake, stenosis, or aneurysms. 
Table 3. Clinical characteristics of patients with and without the event of poor treatment outcomes 


$$
(\mathrm{n}=41) \quad(\mathrm{n}=78)
$$

\begin{tabular}{|c|c|c|c|}
\hline Age, years, mean \pm SD & $72.6 \pm 8.3$ & $73.3 \pm 7.3$ & 0.622 \\
\hline Female patients, $\%$ & 73.2 & 64.1 & 0.317 \\
\hline Weight, kg, mean $\pm \mathrm{SD}$ & $49.4 \pm 9.2$ & $52.5 \pm 11.1$ & 0.128 \\
\hline Signs and symptoms of cranial lesions & 65.9 & 83.3 & 0.03 \\
\hline \multicolumn{4}{|l|}{ at baseline, \% } \\
\hline Headache, \% & 51.2 & 64.1 & 0.173 \\
\hline Abnormal temporal artery, \% & 51.2 & 64.1 & 0.173 \\
\hline Jaw claudication, \% & 36.6 & 32.1 & 0.619 \\
\hline Visual disturbance, \% & 19.5 & 25.6 & 0.454 \\
\hline LVLs detected by imaging at baseline, \% & 78.0 & 46.2 & 0.001 \\
\hline ny lesions of aortic branches ${ }^{\mathrm{c}}, \%$ & 48.8 & 37.2 & 0.222 \\
\hline ny lesions of aorta ${ }^{\mathrm{d}}, \%$ & 53.7 & 30.8 & 0.015 \\
\hline ny structural vascular damage $\mathrm{e}^{\mathrm{e}} \%$ & 31.7 & 19.2 & 0.127 \\
\hline Stenosis of aortic branches ${ }^{\mathrm{c}}, \%$ & 12.2 & 15.4 & 0.637 \\
\hline Aneurysm of aorta, \% & 9.8 & 2.6 & 0.106 \\
\hline Fever at baseline, \% & 24.4 & 36.8 & 0.170 \\
\hline Polymyalgia rheumatica at baseline, $\%$ & 43.9 & 41.0 & 0.763 \\
\hline $\mathrm{CRP}$ at baseline, $\mathrm{mg} / \mathrm{dl}$, & 7.15 & 6.82 & 0.810 \\
\hline median (interquartile range) & $(3.75-11.1)$ & $(2.99-11.2)$ & \\
\hline ichemic heart disease at baseline, \% & 2.4 & 7.7 & 0.235 \\
\hline erebrovascular disease at baseline, $\%$ & 17.1 & 11.5 & 0.400 \\
\hline lypertension at baseline, $\%$ & 39.0 & 44.9 & 0.540 \\
\hline iabetes mellitus at baseline, $\%$ & 19.5 & 17.9 & 0.835 \\
\hline lyperlipidemia at baseline, \% & 22.0 & 29.5 & 0.378 \\
\hline aitial dose of PSL, mg/kg/day, mean \pm SD & $0.76 \pm 0.26$ & $0.75 \pm 0.22$ & 0.799 \\
\hline SL dose at week $4, \mathrm{mg} / \mathrm{kg} /$ day, mean $\pm \mathrm{SD}$ & $0.57 \pm 0.20$ & $0.56 \pm 0.16$ & 0.652 \\
\hline SL dose at week $8, \mathrm{mg} / \mathrm{kg} /$ day, mean $\pm \mathrm{SD}$ & $0.42 \pm 0.16$ & $0.41 \pm 0.14$ & 0.774 \\
\hline
\end{tabular}




\begin{tabular}{|c|c|c|c|}
\hline SL dose at week $12, \mathrm{mg} / \mathrm{kg} /$ day, mean $\pm \mathrm{SD}$ & $0.36 \pm 0.15$ & $0.34 \pm 0.11$ & 0.364 \\
\hline nmunosuppressive drug use at baseline, \% & 15.0 & 9.0 & 0.245 \\
\hline nmunosuppressive drug use during observational period, \% & 75.6 & 28.2 & $<0.001$ \\
\hline MTX for induction therapy, n (\%) & $11(26.8)$ & $9(11.5)$ & - \\
\hline MTX for flare, \% & $12(29.3)$ & - & - \\
\hline CY for induction therapy, \% & $2(4.9)$ & $2(2.6)$ & - \\
\hline CY for flare, \% & $3(7.3)$ & - & - \\
\hline AZA for induction therapy, \% & $7(17.1)$ & $4(5.1)$ & - \\
\hline AZA for flare, $\%$ & $2(4.9)$ & - & - \\
\hline
\end{tabular}

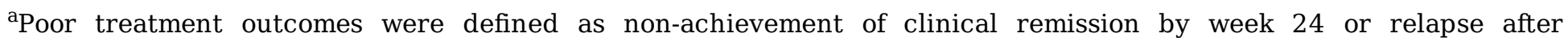
achievement of clinical remission during 52 weeks. ${ }^{b}$ Patients without the event of poor treatment outcomes achieved clinical remission by week 24 and no relapse during 52 weeks. ${ }^{\mathrm{c}}$ Any lesions of aortic branches by imaging included lesions in carotid, vertebral, brachiocephalic, subclavian, axillary artery, pulmonary, renal, or iliac arteries. ${ }^{\mathrm{d}}$ Any lesions of aorta by imaging included lesions in ascending aorta, aorta arch, descending thoracic aorta, or abdominal aorta. eAny structural vascular damage included stenosis, dilatation or aneurysm in lesions of aortic branches and aorta. LVLs, large-vessel lesions; LV, large-vessel; ACR, American College of Rheumatology; CRP, C-reactive protein; PSL, prednisolone; GCs, glucocorticoids; MTX, methotrexate; CY, cyclophosphamide; AZA, azathioprine.

Table 4. Associated factors with poor treatment outcomes ${ }^{\mathrm{a}}$ during 52 weeks 


\begin{tabular}{|c|c|c|c|c|}
\hline & \multicolumn{2}{|c|}{ Univariable analysis } & \multicolumn{2}{|c|}{ Multivariable analysis ${ }^{b}$} \\
\hline & HR $(95 \%$ CI $)$ & $\mathrm{p}$ & HR $(95 \%$ CI $)$ & $\mathrm{P}$ \\
\hline Age, per one year increment & $0.99(0.95-1.03)$ & 0.836 & $1.02(0.97-1.08)$ & 0.388 \\
\hline Female & $1.44(0.72-2.88)$ & 0.396 & $1.28(0.63-2.62)$ & 0.492 \\
\hline Any cranial symptoms at baseline & $0.50(0.26-0.95)$ & 0.034 & $0.83(0.40-1.72)$ & 0.622 \\
\hline Polymyalgia rheumatica at baseline & $1.13(0.61-2.09)$ & 0.699 & $1.30(0.63-2.62)$ & 0.492 \\
\hline LVLs at baseline & $3.20(1.53-6.72)$ & 0.002 & $3.54(1.52-8.24)$ & 0.003 \\
\hline Any lesions of aortic branches ${ }^{\mathrm{c}}$ & $1.44(0.78-2.66)$ & 0.240 & & \\
\hline Any lesions of aorta ${ }^{d}$ & $2.07(1.12-3.82)$ & 0.02 & & \\
\hline Any structural vascular damage $\mathrm{e}^{\mathrm{e}}$ & $1.73(0.90-3.35)$ & 0.102 & & \\
\hline Aneurysm of aorta & $2.76(0.98-7.78)$ & 0.054 & & \\
\hline $\mathrm{CRP}$ at baseline per $1 \mathrm{mg} / \mathrm{dl}$ increment & $1.00(0.95-1.05)$ & 0.930 & & \\
\hline Initial dose of PSL per & $1.01(0.88-1.17)$ & 0.874 & & \\
\hline \multicolumn{5}{|l|}{$0.1 \mathrm{mg} / \mathrm{kg} /$ day increment } \\
\hline Dose of PSL at week 4 per & $1.04(0.86-1.25)$ & 0.685 & & \\
\hline \multicolumn{5}{|l|}{$0.1 \mathrm{mg} / \mathrm{kg} /$ day increment } \\
\hline Dose of PSL at week 8 per & $1.03(0.83-1.29)$ & 0.785 & & \\
\hline \multicolumn{5}{|l|}{$0.1 \mathrm{mg} / \mathrm{kg} /$ day increment } \\
\hline Dose of PSL at week 12 per & $1.13(0.87-1.46)$ & 0.356 & & \\
\hline \multicolumn{5}{|l|}{$0.1 \mathrm{mg} / \mathrm{kg} /$ day increment } \\
\hline Immunosuppressive drug use at baseline & $1.54(0.65-3.67)$ & 0.330 & & \\
\hline
\end{tabular}

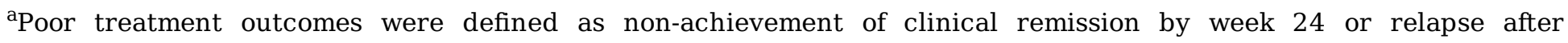
achievement of clinical remission during 52 weeks. ${ }^{b}$ Age, sex, any cranial symptoms, and polymyalgia rheumatica were selected as covariates of interest. ${ }^{\mathrm{c}}$ Any lesions of aortic branches by imaging included lesions in carotid, vertebral, brachiocephalic, subclavian, axillary artery, pulmonary renal or iliac arteries. ${ }^{\mathrm{d}}$ Any lesions of aorta by imaging included lesions in ascending aorta, aorta arch, descending thoracic aorta, or abdominal aorta. ${ }^{\mathrm{e} A n y}$ structural vascular damage included stenosis, dilatation or aneurysm in lesions of aortic branches and aorta. LVLs, large vessel lesions; CRP, C-reactive protein; PSL, prednisolone. 


\section{Figures}

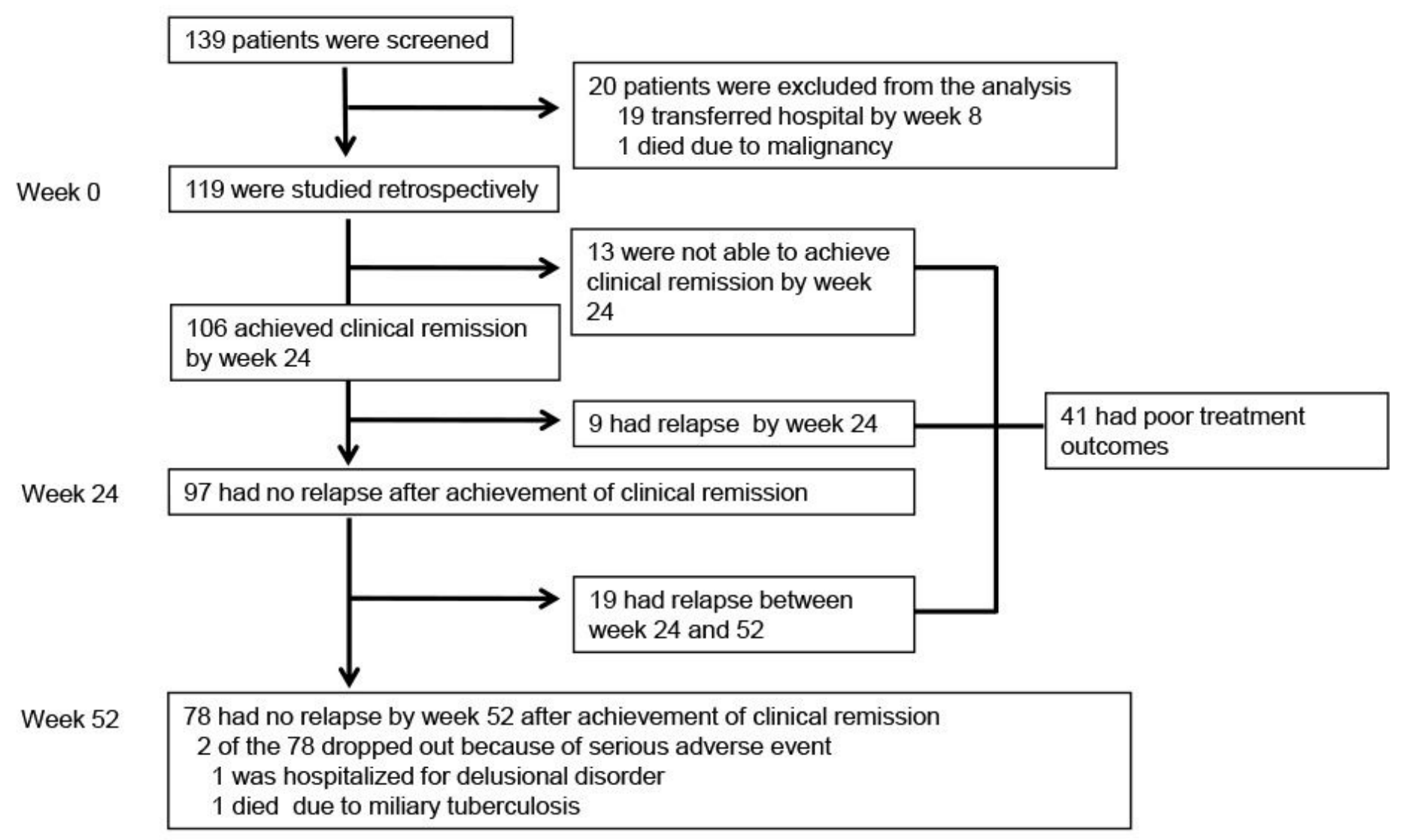

Figure 1

Screening, follow-up of the patients, and treatment outcomes. Clinical remission and relapse were evaluated in 119 newly-diagnosed patients who were observed for more than 24 weeks. Thirteen had worsening of clinical signs and symptoms or persisted elevation of CRP and were not able to achieve clinical remission. Nine had relapse after achievement of clinical remission between week 0 and 24, and 97 had no relapse at week 24 after achievement of clinical remission. Nineteen of the 97 had relapse between week 24 and 52, and 78 had no relapse at week 52 after achievement of clinical remission. Overall, 41 had poor treatment outcomes. 


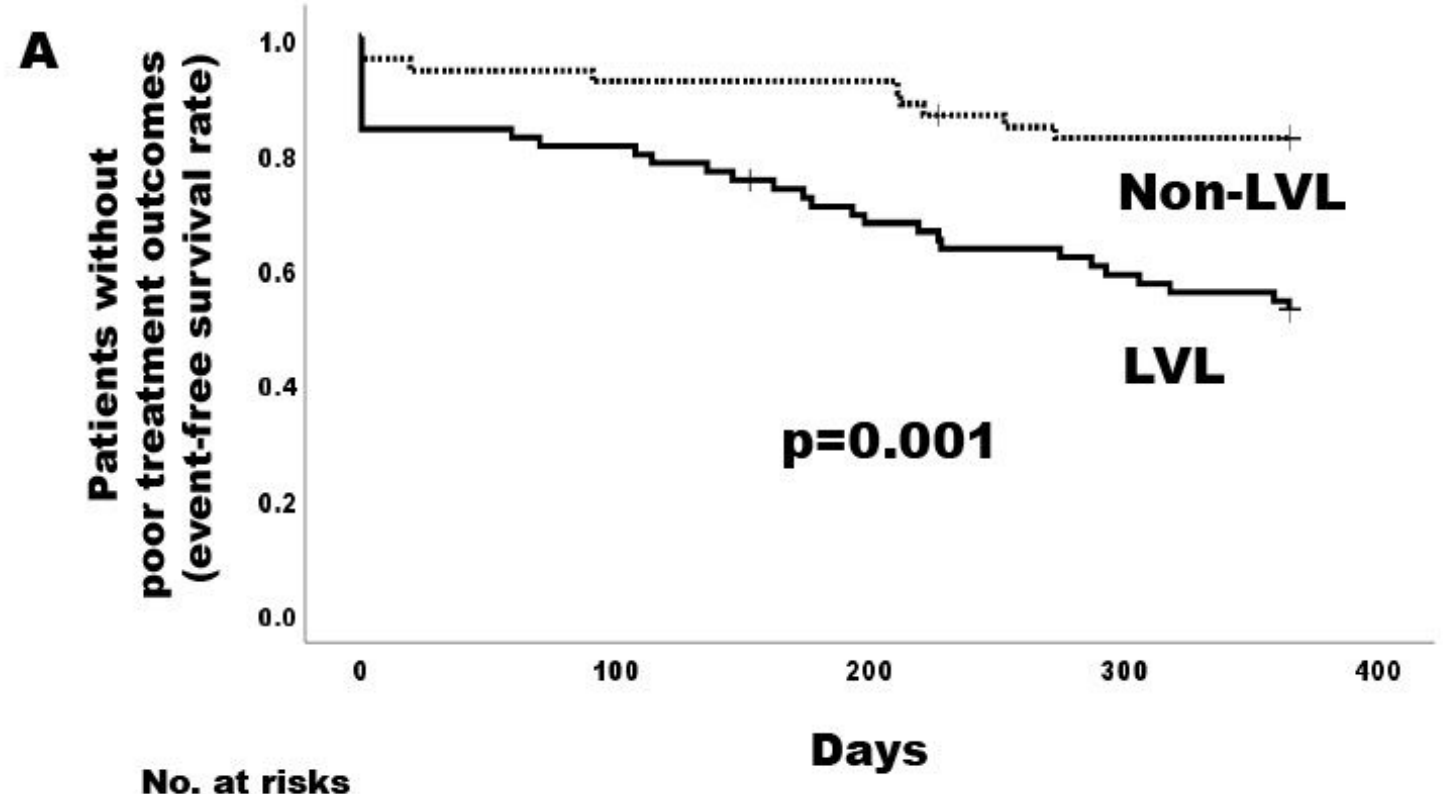

$\begin{array}{lllllllll}\text { Non-LVL } & 51 & 48 & 47 & 47 & 46 & 42 & 41 & 40 \\ \text { LVL } & 68 & 56 & 54 & 50 & 45 & 41 & 38 & 35\end{array}$

B

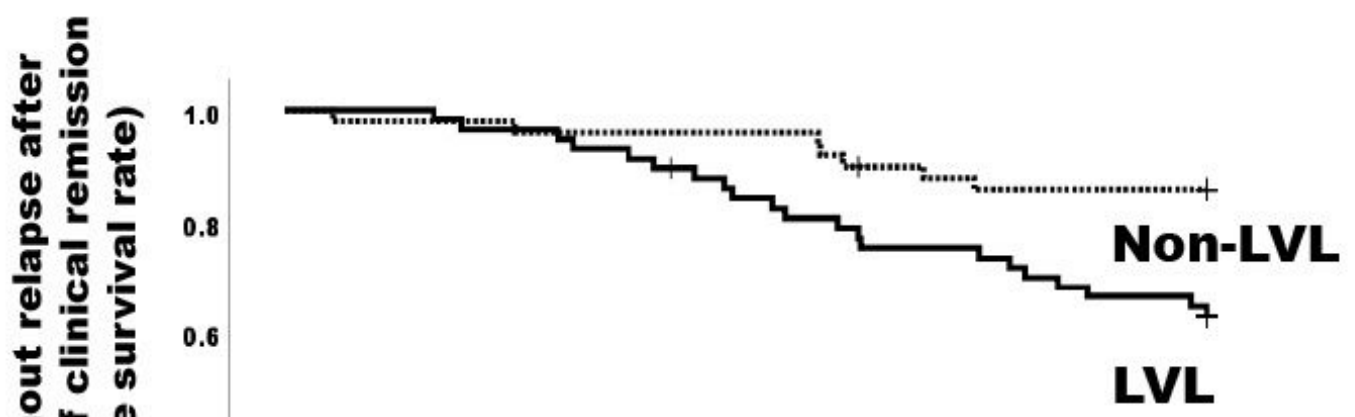

$\mathbf{p}=0.01$

No. at risks

$\begin{array}{lllllllll}\text { Non-LVL } & 49 & 49 & 47 & 47 & 46 & 42 & 41 & 40\end{array}$

$\begin{array}{lllllllll}\text { LVL } & 57 & 56 & 54 & 50 & 54 & 42 & 39 & 35\end{array}$

Figure 2

Event-free curve in patients who were observed for 24 weeks or longer. (A) Time to poor treatment outcomes analyzed in all 119 patients who were observed for 24 weeks or longer. Patients who did not achieve clinical remission by week 24 were considered to have had an event at week 0 . (B) Time to the first relapse in 106 patients who achieved clinical remission by week 24 . 


\section{Supplementary Files}

This is a list of supplementary files associated with this preprint. Click to download.

- additionalfileGCAART2020.1.20.docx 